\title{
The Development of Ecchymosis after Administration of Convalescent Serum in a Patient with COVID-19 Associated with Thrombocytosis
}

\author{
$\underline{\text { Rajashree Khot }}{ }^{1}$, Sunita D Kumbhalkar ${ }^{1}$, Richa Juneja ${ }^{2}$, Prashant P Joshi ${ }^{1}$ \\ ${ }^{1}$ Department of General Medicine, AIIMS, Nagpur, Maharashtra, India \\ ${ }^{2}$ Department of Pathology (Haematology), AlIMS, Nagpur, Maharashtra, India
}

Received: $21 / 07 / 2021$

Accepted: $27 / 08 / 2021$

Published: $13 / 09 / 2021$

How to cite this article: Khot R, Kumbhalkar SD, Juneja R, Joshi PP. The development of ecchymosis after administration of convalescent serum in a patient with COVID-19 associated with thrombocytosis. EJCRIM 2021;8: doi:10.12890/2021_002782.

Conflicts of Interests: The authors declare there are no competing interests.

Acknowledgements: We are grateful to Dr Vibha Dutta, SM, Director and CEO, All India Institute of Medical Sciences, Nagpur for her support and encouragement.

Funding: All India Institute of Medical Sciences, Nagpur supported the publication of this report.

This article is licensed under a Commons Attribution Non-Commercial 4.0 License

\section{ABSTRACT}

COVID-19 can have an unpredictable and severe course, leading to many hypotheses regarding its pathophysiology and clinical manifestations. Haematological manifestations are a significant predictor of disease severity. The most common observation is lymphopenia with an increased neutrophil:lymphocyte ratio. Platelets have been implicated in thrombogenic events, but the most frequently reported abnormality is mild thrombocytopenia.

Here we present an interesting case of a patient with moderate COVID-19 who presented with cutaneous ecchymoses and thrombocytosis, and discuss this paradox.

\section{LEARNING POINTS}

- Bleeding manifestations such as ecchymoses can occur as an idiosyncratic reaction to the administration of convalescent plasma therapy in COVID-19.

- Thrombocytosis can occur in COVID-19 and could be a contributory factor to disease vasculopathy.

\section{KEYWORDS}

COVID-19, thrombocytosis, convalescent plasma reaction, ecchymoses

\section{CASE DESCRIPTION}

A 55-year-old male patient was admitted to the Covid ward of a tertiary care centre with complaints of high-grade, intermittent fever and dry cough of 8 days duration, breathlessness for 2 days and an RT-PCR positive test for COVID-19. He was a non-smoker and non- alcoholic. He denied any history of bleeding following minor trauma or surgical procedures. There was no family history of a bleeding disorder. He had diabetes mellitus and systemic hypertension.

On admission, the patient had an $\mathrm{SpO} 2$ of 94\%, which dropped to $90 \%$ after the 6 minute walk test. He was started on oxygen support with a venturi mask at $6 \mathrm{l} / \mathrm{min}$. Investigations revealed that his AST and ALT were elevated with values of $192.1 \mathrm{IU} / \mathrm{ml}$ and $186.5 \mathrm{IU} / \mathrm{ml}$, respectively, while serum alkaline phosphatase and serum bilirubin were normal. His serum creatinine was $1.8 \mathrm{mg} / \mathrm{dl}$. Hence, remdesivir, favipiravir, doxycycline, azithromycin and tocilizumab were contraindicated. All inflammatory markers were elevated (Table 1). The chest 
x-ray showed consolidation in the right lower zone (Fig. 1A). The patient was started on oral hydroxychloroquine, subcutaneous enoxaparin and IV methylprednisone, according to national guidelines, and supportive treatment. He was breathless and desaturating.

After review of all the options, he was given $200 \mathrm{ml}$ convalescent plasma therapy (ConvP) on the second day of admission. The next morning, he developed a large ecchymotic patch over the left antecubital region. Within 24 hours it had extended proximally and distally to involve the entire left upper limb (Fig. 2A). Over the next 24 hours, the patient developed ecchymoses over the right antecubital region and also over his abdomen at the site of insulin injections.
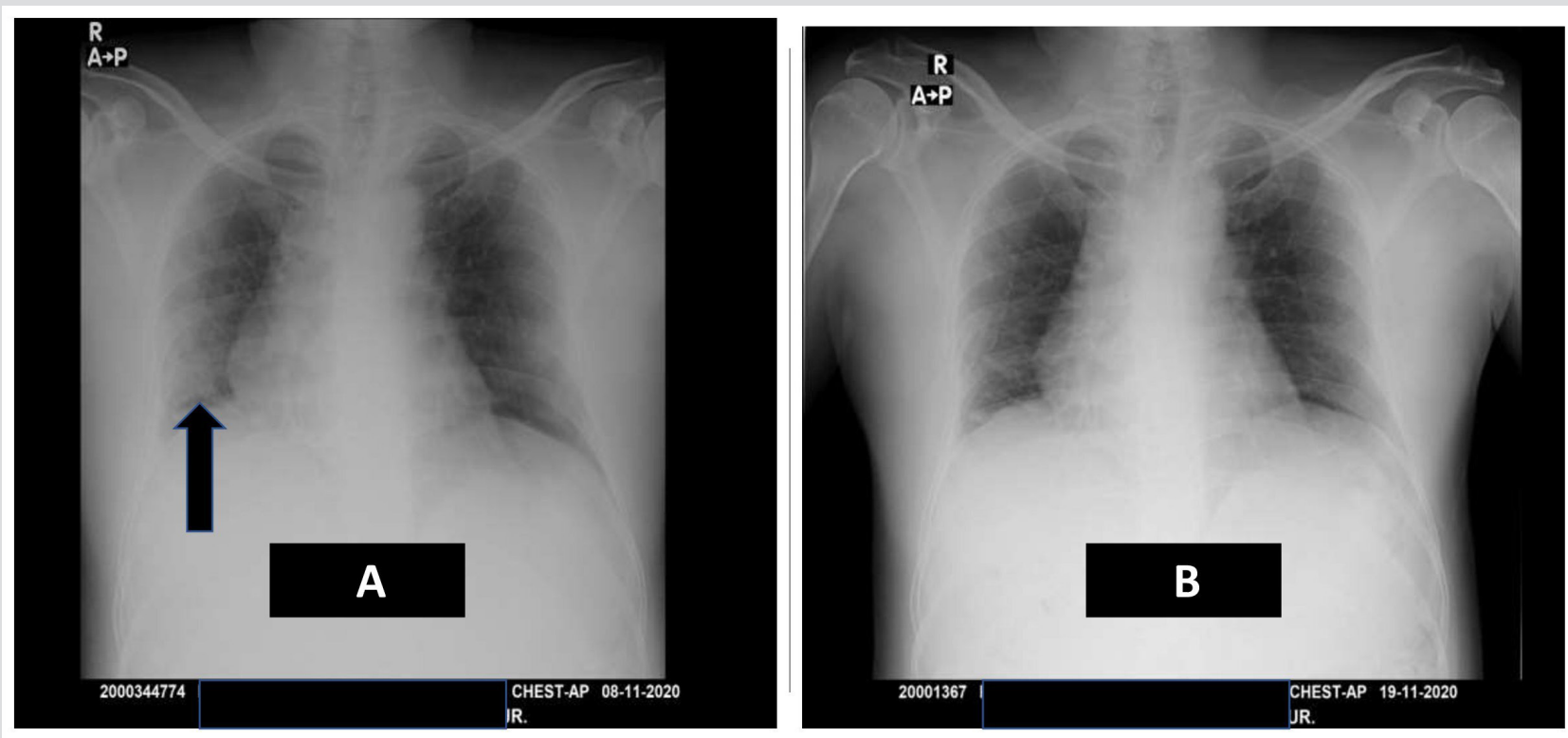

Figure 1. (A) X-ray of the chest showing consolidation in the right lower zone (black arrow). (B) Normal chest $x$-ray at follow-up
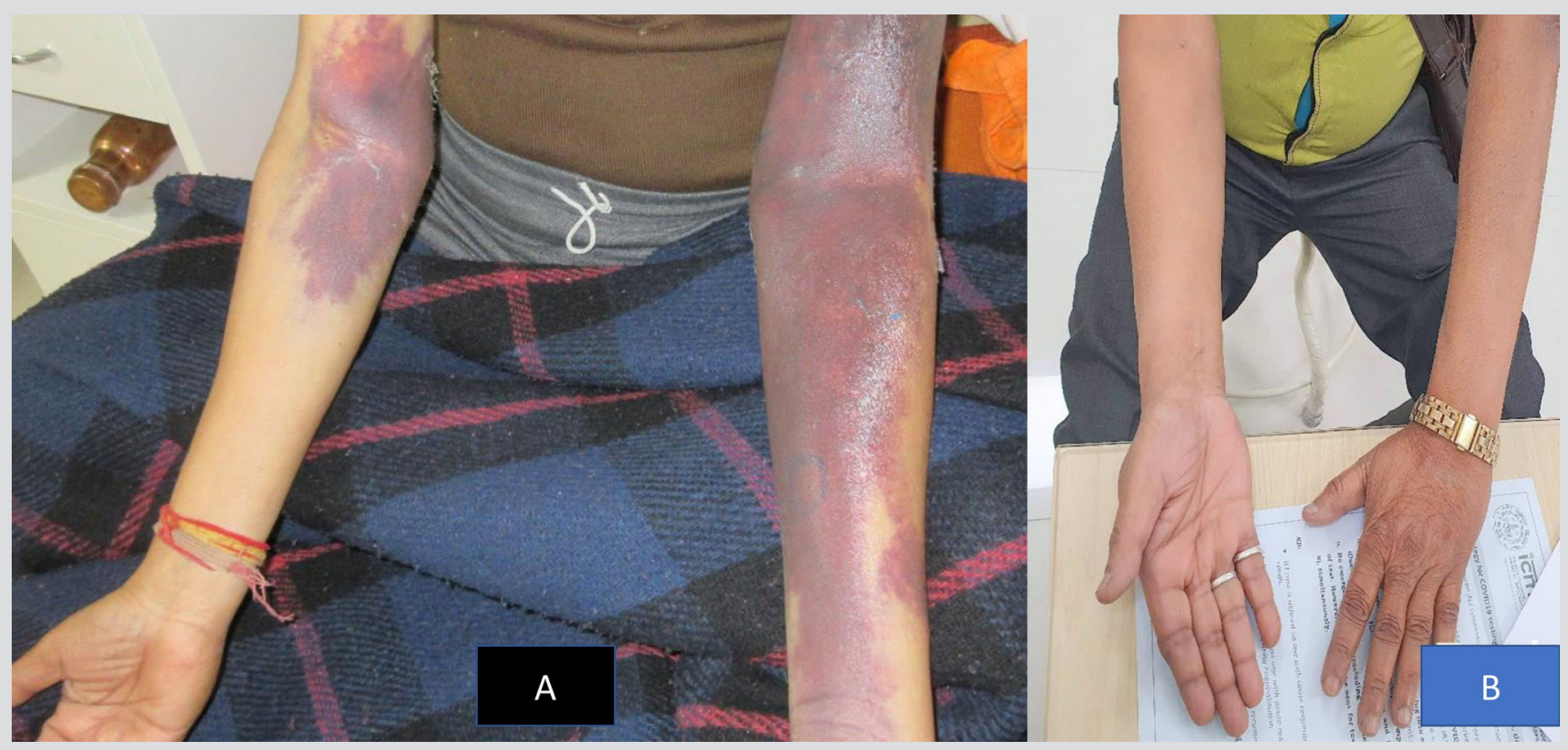

Figure 2. (A) Ecchymoses over both arms. (B) Complete clearing of ecchymoses at follow-up 


\begin{tabular}{|c|c|c|c|c|c|c|c|}
\hline & \multicolumn{7}{|c|}{ Day of Investigation } \\
\hline & On admission & $\begin{array}{l}\text { Day } 3 \\
\text { (ecchymosis) }\end{array}$ & Day 4 & Day 6 & Day 7 & $\begin{array}{l}\text { Day } 11 \\
\text { (discharge) }\end{array}$ & $\begin{array}{l}\text { Day } 18 \\
\text { (follow-up) }\end{array}$ \\
\hline$H b \%(g / d)$ & 12.8 & 13.9 & 12.6 & 10.6 & & 10.3 & 12 \\
\hline$T L C / m l$ & 8,490 & 13,910 & 13,930 & 20,370 & & 16,210 & 8390 \\
\hline NLR & 3.8 & 5.7 & 7 & 12 & & 9.3 & 2.4 \\
\hline Platelets/ml & $267 \times 10^{6}$ & $410 \times 10^{6}$ & $436 \times 10^{6}$ & $682 \times 10^{6}$ & $949 \times 10^{6}$ & $693 \times 10^{6}$ & $395 \times 10^{6}$ \\
\hline $\begin{array}{l}\text { Serum bilirubin } \\
\text { (mg/dl) }\end{array}$ & 0.85 & & & & & & \\
\hline AST(u/L) & 192.1 & 107.5 & 113 & 48.6 & & 35 & 24.2 \\
\hline $\operatorname{ALT}(u / L)$ & 186.5 & 64.1 & 122 & 82.5 & & 46.4 & 31.2 \\
\hline $\begin{array}{l}\text { Serum creatinine } \\
\text { (mg/dl) }\end{array}$ & 1.8 & 2.27 & 0.96 & 1.56 & & 1.23 & 0.90 \\
\hline $\begin{array}{l}\text { Serum CRP } \\
\text { (mg/dl) }\end{array}$ & 35 & & & 22.8 & & 11.8 & \\
\hline $\begin{array}{l}\text { Serum ferritin } \\
(\mathrm{ngm} / \mathrm{ml})\end{array}$ & 975.7 & & 394 & 233 & & 149 & \\
\hline $\begin{array}{l}\text { Serum D-dimer } \\
(\mathrm{ngm} / \mathrm{ml})\end{array}$ & 526 & & 123 & $<100$ & & & \\
\hline $\begin{array}{l}\text { Serum IL-6 } \\
(\rho g m / \mathrm{ml})\end{array}$ & 33.8 & & & & & 5.6 & \\
\hline $\begin{array}{l}\text { Serum } \\
\text { procalcitonin } \\
(\mathrm{mgm} / \mathrm{m} /))\end{array}$ & & 0.13 & & & & & \\
\hline
\end{tabular}

Table 1. Laboratory results. The bold values are outside normal range.

NLR: neutrophil:lymphocyte ratio; TLC: total leucocyte count.

The differential diagnosis included (a) an idiosyncratic reaction to transfused plasma, (b) heparin-induced thrombocytopenia, (c) hepatic coagulopathy, (d) COVID-19-related cutaneous ecchymosis and (e) unmasking of an inherited coagulopathy (e.g., fibrinogen or factor XIII deficiency). His complete blood count (CBC) was surprising as he had an elevated platelet count of $464 \times 10^{6} / \mathrm{ml}$. He also had an elevated total leucocyte count and his neutrophil:Iymphocyte ratio (NLR) had worsened to 5.7. However, his liver enzyme levels had decreased (Table 1). 
His coagulation profile was normal with a prothrombin time (PT) of 96\%, an International Normalized Ratio (INR) of 1 and an activated partial thromboplastin time (aPTT) $32 \mathrm{sec}$ (normal: $29 \mathrm{sec}$ ). Serum procalcitonin was normal, suggesting the absence of sepsis. Steroids and enoxaparin were immediately discontinued. He was given symptomatic treatment and monitored over the next few days. His platelet count continued to increase, reaching a peak of $949 \times 10^{6} / \mathrm{ml}$ on Day 7 . He then started to recover. His oxygen requirement decreased, liver and kidney function improved, and inflammatory markers declined. His ecchymotic patches began to fade and over the next 15 days they completely disappeared (Fig. 2B). His chest x-ray became normal (Fig. 1B).

\section{DISCUSSION}

COVID-19 has many clinical presentations. Although pulmonary manifestations are predominant, extrapulmonary involvement and complications have also been reported. Haematological manifestations in COVID-19 include leucocytosis, and lymphopenia with activated plasma lymphocytoid cells, with a consequent increase in the NLR. Increased NLR is an important predictor of severity and mortality. Platelet abnormalities in COVID-19 range from a mild reduction in platelet count, to abnormalities of platelet activation and aggregation,and the presence of giant platelets. Distinct platelet-related patterns in a full blood count such as an elevated platelet-to-lymphocyte ratio or lower platelet-to-neutrophil ratio appear to be associated with the development of more severe disease ${ }^{[1]}$. An increased platelet count has been rarely reported. Both bleeding and thrombotic complications have been described in COVID-19 patients, with a complex interplay between platelets and coagulation. We describe an interesting case of ecchymosis in COVID-19 due to a different mechanism.

This patient presented with moderate Covid infection. However, 12 hours after ConvP infusion he developed large ecchymoses. ConvP has previously been used for the treatment of SARS-CoV-1, influenza and varicella zoster infection. Reported adverse reactions to ConvP range from mild fever to allergic reactions to life-threatening bronchospasm, transfusion-related acute lung injury and circulatory overload. Noninfectious problems with transfusions can further exacerbate respiratory symptoms in COVID-19 patients. A transient elevation of body temperature by $0.5-1.5^{\circ} \mathrm{C}$ within 2 hours of transfusion has been reported. However, extensive ecchymoses as seen in our patient have not previously been described. Recent studies have not presented conclusive evidence of the benefits of ConvP therapy in COVID-19 and have reported that ConvP was not associated with progression to severe COVID-19 or with improvement in all-cause mortality ${ }^{[2]}$.

A COVID-19 retrospective study found that the overall bleeding rate was very low $(4.8 \% ; 95 \% \mathrm{Cl} 2.9-7.3)$, with only one major bleeding episode reported. Thrombocytopenia (platelet count $<150 \times 10^{9} /$ l) and elevated D-dimer levels $>2,500 \mathrm{ng} / \mathrm{ml}$ at initial presentation were predictive of bleeding complications in critically ill patients ${ }^{[3]}$. In our patient, investigations ruled out heparin-induced thrombocytopenia, bleeding diathesis and sepsis.

Paradoxically, despite the ecchymoses, the patient's platelet count was continuously increasing, reaching 940x10\%/ml. Platelet abnormalities in COVID-19 have been studied, with most investigators reporting mild thrombocytopenia in COVID-19. A meta-analysis of 7,613 COVID-19 patients revealed that those with severe disease had a lower platelet count than those with non-severe disease ${ }^{[4]}$.

We did not find any reports of thrombocytosis in COVID-19 patients. However, in 2003, Wong et al. observed that $49 \%$ of patients with SARS-CoV-1 infection had rebound thrombocytosis ${ }^{[5]}$. Recently, Comer et al. also reported that their cohort had increased levels of thrombopoietin, which stimulates thrombopoiesis. This resulted in the production of giant platelets with release of platelet-activated cytokines having an important role in the pathogenesis of COVID-19 complications ${ }^{[1]}$. However, none of their patients had the marked thrombocytosis seen in our case. Thrombocytosis may be due to hyperstimulation of bone marrow.

Our patient improved with supportive management. The extensive ecchymosis and temporal relationship with ConvP therapy suggested ecchymoses was a complication of the administration of ConvP rather than a bleeding or cutaneous manifestation of COVID-19.

\section{REFERENCES}

1. Comer SP, Cullivan S, Szklanna PB, Weiss L, Cullen S, Kelliher S, et al. COVID-19 induces a hyperactive phenotype in circulating platelets. PLoS Biol 2021;19(2):e3001109. doi: 10.1371/journal.pbio.3001109.

2. Nagoba B, Gavkare A, Jamadar N, Mumbre S, Selkar S. Positive aspects, negative aspects and limitations of plasma therapy with special reference to COVID-19. J Infect Public Health 2020;13:1818-1822.

3. Al-Samkari H, Karp Leaf RS, Dzik WH, Carlson JCT, Fogerty AE, Waheed A, et al. COVID-19 and coagulation: bleeding and thrombotic manifestations of SARS-CoV-2 infection Blood x2020;136(4):489-500. doi: 10.1182/blood.2020006520.

4. Jiang SQ, Huang QF, Xie WM, Lv C, Quan XQ. The association between severe COVID-19 and low platelet count: evidence from 31 observational studies involving 7613 participants. Br J Haematol 2020;190(1):e29-33. 